КАИНИЧЕСКОЕ ТЕЧЕНИЕ

ВОСПАЛИТЕАЬНЫХ ЗАБОЛЕВАНИЙ ПОЛОСТИ РТА У БОЛЬНЫХ ОПИЙНОЙ

НАРКОМАНИЕЙ В ЗАВИСИМОСТИ

ОТ СТАЖА УПОТРЕБАЕНИЯ

ПСИХОТРОПНЫХ ВЕЩЕСТВ

АИТЕРАТУРНЫЙ ОБЗОР

\section{Актуальность проблемы}

Прямую угрозу нации на сегодняшний день представляет наркомания, приобретающая характер эпидемии. В мире зарегистрировано 52-185 млн человек (1-3\% населения Земли) систематически злоупотребляющих наркотиками $[10,12]$. По данным зарубежной и отечественной литературы потребление населением наркотических препаратов постоянно растет [3, 8]. Доля наркоманов, приходящая на Российскую Федерацию по данным НИИ Наркологии составляет около 5 млн человек. Наиболее злокачественной признана опийная наркомания, которая составляет $82,9 \%$ от общего числа наркоманий $[10,12]$.

В настоящее время наркомания представляет собой актуальную проблему не только в социальном, но и в биологическом, и медицинском аспектах [8, 17]. Применение наркотических веществ приводит к интоксикации организма и нарушению функций различных органов и систем. Поражаются также различные структуры полости рта.

\section{ОСЛОЖНЕННЫЙ КАРИЕС}

При стаже наркотической зависимости более 5 лет у пациентов часто развивается множественный кариес, переходящий в пульпит и периодонтит, которые отличаются вялотекущим течением [12]. Картина «безболевого» кариеса и пульпита очень специфична для пациентов-наркоманов [4]. Часто у наркоманов наблюдается картина полного отсутствия коронок всех зубов на альвеолярном отростке. При этом стоматологических жалоб нет [4]. Выявляется сильнейшая дистрофия сосудистого нервного пучка зуба. Даже при жизни пульпа зуба выглядит как грязная белая нить [4]. Доказано повышение показателей электроодонтодиагностики пульпы интактных зубов (в 9-18 раз), позволяющее считать

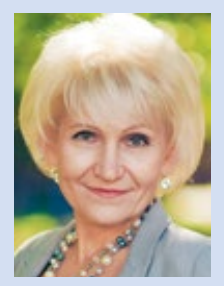

Токмакова С.И. д.м.н., профессор, зав. кафедрой терапевтической стоматологии ГБОУ ВПО АГМУ, г. Барнаул, agmuterst@mail.ru

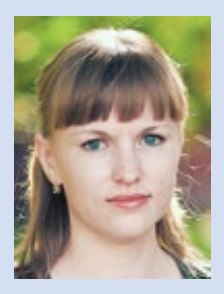

Луницына Ю.В. к.м.н., ассистент кафедры терапевтической стоматологии ГБОУ ВПО АГМУ, г. Барнаул, lunizyna.julja@mail.ru

\section{Резюме}

Представлен обзор данных отечественной и зарубежной литературы о влиянии опийной наркозависимости на развитие воспалительных заболеваний полости рта. Показана распространенность различной патологии полости рта у наркозависимых больных и зависимость тяжести поражения от длительности приема психотропного вещества; отмечены особенности течения заболеваний у данной группы пациентов.

Ключевые слова: опийная наркомания, полость рта, воспаление.

THE CLINICAL COURSE OF INFLAMMATORY DISEASES OF THE ORAL CAVITY IN PATIENTS WITH OPIOID ADDICTION, DEPENDING ON THE LENGTH OF USE OF PSYCHOTROPIC SUBSTANCES (LITERATURE REVIEW)

Tokmakova S. I., Lunitsyna Y.V.

\section{The summary}

The review of the data of domestic and foreign literature on the impact of opiate dependence on the development of inflammatory diseases of the oral cavity. Shows the prevalence of various pathologies of the oral cavity in patients with drug dependence and the severity of the duration of use of psychotropic substances; marked characteristics of the disease in this group of patients.

Keywords: opiate addiction, oral cavity, inflammation. 
данный признак патогноманичным при опийной зависимости $[2,9,10]$.

\section{ВОСПАЛИТЕЛЬНЫЕ ЗАБОЛЕВАНИЯ ПАРОДОНТА}

Морфологические изменения в тканях пародонта характеризуются прогрессированием реакций воспаления, склерозирования и атрофии и обусловливают гингивит, пародонтит $[15,16]$. Микрофлора зубного налета в патогенезе воспалительных заболеваний пародонта у потребителей наркотиков-опиатов играет вторичную роль [10].

С увеличением продолжительности применения опиоидных наркотиков (более 1,5 лет) воспалительно-дистрофические процессы в тканях пародонта значительно усиливаются $[12,18]$. В ходе исследования (Фурсова А.Д., 2009) установлено, что у пациентов в возрасте до 30 лет потребляющих наркотики менее 1,5 лет существенных изменений в полости рта не отмечается; с увеличением стажа применения наркотиков в возрасте до 30 лет изменения нарастают и выражаются в развитии следующих форм патологии: хронический катаральный, гипертрофический; язвенный и смешанные формы гингивита. У пациентов более старшего возраста (с 31 до 40 лет) с различным стажем преимущественно наблюдаются явления генерализованного хронического пародонтита (как правило, средней степени тяжести), отмечены так же явления гипертрофии краевого пародонта. Особенностью проявления патологии полости рта у наркоманов, являются вялотекущее течение заболеваний, медленное купирование острых явлений [12], прогрессирующая деструкция костной ткани $[1,3,5]$. Надо отметить, что более тяжелые формы патологии пародонта, имеют место у пациентов молодого возраста, имеющих значительный наркотический стаж приема наркотиков на фоне соматических нарушений. Результаты исследований свидетельствует о том, что распространенность воспалительных заболеваний пародонта у пациентов, страдающих наркотической зависимостью от опиатов, в 2,2 раза выше, чем у лиц, не употребляющих наркотики [12]. Гингивит у наркоманов встречается в 1,5 раза (88,9\% случаев) $[8,13]$, а пародонтит - в 10 раз чаще, чем у пациентов, не принимающих наркотик (64,1\% случаев) $[3,5,12]$. Клинические показатели PMA и Rüssel, характеризующие степень вовлечения тканей пародонта в воспалительный процесс, наглядно отображают нарастание интенсивности поражения тканей пародонта у пациентов, страдающих наркотической зависимостью от опиатов [12]. Гигиеническое состояние полости рта у наркоманов значительно хуже, чем у лиц, не употребляющих наркотических веществ (ИГ $=2,54 \pm 0,34)[8,19]$.

Рентгенологическая картина пародонта и костной ткани челюстей у опиоидзависимых лиц в динамике роста срока употребления наркотиков, характеризуется нарушением контактов между зубами, неравномерным снижением высоты межзубных перегородок, расширением периодонтальной щели с образованием костных карманов, разрыхлением компактной пластинки межальвеолярных перегородок и нарушением структуры костной ткани челюстей, а также достоверным снижением оптической плотности нижнечелюстной кости в зонах межальвеолярных перегородок в первую очередь, а в дальнейшем и в теле челюсти [10]. В данной группе больных увеличивается частота и тяжесть переломов челюстей, причем значительно возрастает число осложнений, таких как остеомиелит, остит и др. [12], возрастает число зубочелюстных деформаций, жевательная эффективность зубочелюстной системы снижается в 1,8 раза [10].

\section{ВОСПАЛИТЕЛЬНЫЕ ИЗМЕНЕНИЯ СЛИЗИСТОЙ ОБОЛОЧКИ ПОЛОСТИ РТА}

Для пациентов, страдающих наркотической опийной зависимостью, характерен бледный цвет слизистой оболочки полости рта [8]. Хроническая опийная интоксикация вызывает снижение тактильной, болевой, температурной чувствительности десны и вкусовой рецепция языка (в среднем в $2,5-3$ раза) $[6,10]$. Гистологически у опиоидозависимых пациентов выявляют следующие изменения: гиперсекреция слизистых клеток, их апикальная и (или) тотальная десквамация, многочисленные слизистые гранулы, появление слюнных телец обтурирующего характера, наличие внутриклеточных и свободно находящихся среди структур скоплений бактериальной микрофлоры, набухание и очаговая деструкция базальной мембраны, отек интерстиция. Наличие инфильтрата в стенке сосуда и вокруг него является морфологическим признаком васкулита [3, 5]. На слизистой оболочке полости рта и губ выявляются хейлиты, кандидоз, афтозный стоматит, герпес и очаги лейкоплакии $[7,12]$.

Смешанная слюна опиоидзависимых больных характеризуется снижением скорости секреции, $\mathrm{pH}$, уровня неорганического фосфора, коэффициента поверхностного натяжения слюны, увеличением количества осадка и вязкости, уровня кальция, $\mathrm{Ca} / \mathrm{P}$ коэффициента и количества белка [10]. Повышение кислотности и изменение биохимического состава способствует нарушению всех функций слюны 
(защитной, бактерицидной, минерализирующей, транспортной и пр.) [4]. Чистый секрет околоушных слюнных желез характеризуется снижением в среднем в 2 раза, по сравнению с показателями у здоровых лиц, скорости саливации и вязкости $[2,8,10,14]$. Выраженность патоморфологических изменений слюнных желез пропорциональна длительности употребления психоактивных веществ $[3,5]$. В осадке ротовой жидкости при цитологическом исследовании выявляются изменения эпителиоцитов слизистой полости рта, тяжесть которых зависит от длительности приема наркотика [8].

\section{ОДОНТОГЕННЫЕ ВОСПАЛИТЕЛЬНЫЕ ЗАБОЛЕВАНИЯ}

Причиной госпитализации наркоманов в хирургические стационары в 92\% случаев являются гнойно-септические осложнения (абсцесс, флегмона, лимфаденит, тромбофлебит и др.) и лишь $8 \%$ обращаются за хирургической помощью по поводу травмы или урогентной абдоминальной патологии. К тому же, гнойно-септические осложнения у $14 \%$ наркоманов - это различные проявления сепсиса, которые требуют особого подхода в плане диагностики, предоперационной подготовки, радикальной хирургической операции первичного гнойного очага, интенсивной терапии в послеоперационном периоде.

Периоститы у наркоманов чаще имеют острое или же обострившееся хроническое течение, характеризуются умеренно выраженным или вялотекущим клиническим течением. Отличительной особенностью является то, что слизистая оболочка альвеолярного отростка и переходной складки имеет застойно-синюшный вид, рыхлая. Сглаженности переходной складки не обнаруживается, гиперпластических явлений со стороны периоста не определяется. Рентгенологическая картина при периостите соответствует таковой у больных с периодонтитом (определяются остеопорозные очаги в челюсти).

Одонтогенные остеомелиты челюстей у наркозависимых пациентов имеют особенности клинического проявления. Они характеризуются хроническим течением и обширностью поражения (разлитой или диффузный характер). Особенностью одонтогенных остеомиелитов у наркозависимых пациентов является хронический, прогрессирующий и быстротекущий характер клинического течения, всегда присутствует обнажение костной ткани альвеолярного отростка, которая имеет нежизненный (тусклый, матовый, грязно-серый и др.) вид, характеризуется отсутствием грануляционной ткани в патологическом очаге, отсутствием выраженной гиперемии слизистой оболочки и наличием утолщения околочелюстных мягких тканей, их малой болезненностью. Для этих больных характерно неудовлетворительное заживление постэкстракционных ран и низкая эффективность проводимых общепринятых лечебных мероприятий. При осложнениях клинического течения хронических одонтогенных остеомиелитов челюстей нередко возникают абсцессы и флегмоны мягких тканей челюстно-лицевой области и шеи, которые у наркозависимых пациентов имеют свои особенности течения.

Абсцессы и флегмоны [11] имеют затяжной характер течения, отличаются обширностью поражения мягких тканей, характеризуются выраженной инфильтрацией подлежащих тканей, гиперемией кожных покровов, наличием на коже единичных или множественных свищей, через которые выделяется гнойное содержимое, присутствием гнойно-некротических очагов. Послеоперационные раны заживают вяло, медленно заполняются вялыми единичными грануляциями, которые пропитаны серозно-гнойным экссудатом. Нередко края послеоперационных ран разведены, и через открытые раны мягких тканей обнажается костная ткань челюсти, которая имеет желтый цвет и покрыта серозно-слизистым экссудатом. Края кожи послеоперационных ран рыхлые, гиперемированы, истончены, легко разрываются при натяжении, частично некротизированы. Традиционное консервативное лечение послеоперационных ран недостаточно эффективно, поэтому в дальнейшем размеры воспалительно-измененных мягких тканей продолжают увеличиваться и на коже появляются новые свищевые ходы со скудным гнойным отделяемым, а также гнойно-некротические очаги.

\section{Заключение}

Профессиональный подход в лечении воспалительных заболеваний врачом-стоматологом должен осуществляться с учетом особенностей, характерных для данного контингента больных: хроническое, вялотекущее течением заболевания, разлитой или диффузный характер, медленное купирование острых явлений, увеличение частоты и тяжести осложнений, безболезненность и отсутствие жалоб, низкая эффективность проводимых общепринятых лечебных мероприятий.

\section{ЛИТЕРАТУРА}

1. Андреева Н.Б. Изменения в тканях пародонта при хронической морфинной интоксикации и применение антиокси- 
данта дибунола с целью коррекции (экспериментальное исследование): автореф. дис. канд. мед. наук. - Москва, 2002. - 20 c.

2. Бимбас Е.С. Ранние проявления приема опиатов в полости рта у подростков // Институт стоматологии. - 2004. №1. - С.62.

3. Горячев Д.Н. Морфофункциональная оценка состояния тканей пародонта и слюнных желез у наркологических пациентов: автореф. дис. канд. мед. наук. - Казань, 2011. - 19 C.

4. Гусев Ю.С., Черемисина И.Ю. Стоматологические аспекты проблемы организации лечебной помощи больным наркоманией и СПИДом. // Доклады Омского отделения международной академии наук экологии и безопасности жизнедеятельности. - Том 1, вып.1. - Омск, 2000. - С. 76.

5. Колчев А.А. Клинико-лабораторная характеристика состояния органов и тканей полости рта у подростков больных опийной наркоманией: автореф. дис. канд. мед. наук. - М., 2005. - 21 c.

6. Лохов Е.В. Характеристика основных стоматологических заболеваний у лиц с различной резистентностью зубов на фоне гепатитов и парентеральной наркомании: автореф. дис. канд. мед. наук. - Омск, 2000, - 19 с.

7. Могильникова М.В., Сидельникова Е.В. Стоматологические изменения у курильщиков и наркоманов // Доклады Омского отделения МАНЭБ. - Омск, 2000. - В.1. - С. 61.

8. Надымова И.А. Диагностика и лечение ранних проявлений патологии полости рта у подростков при героиновой наркомании: автореферат диссертации на соискании ученой степени кандидата медицинских наук. - Екатеринбург, 2006. - 22 с.

9. Сизиков А.В., Струев И.В. Стоматологический статус у больных опийных наркоманов в молодом возрасте // Актуальные вопросы педиатрии. - Омск, 2000. - С. 84-85.
10. Струев И.В. Патогенетическое обоснование комплекса диагностических и лечебно-профилактических мероприятий при стоматологической реабилитации больных опийной наркоманией: автореф. дис. док. мед. наук. - Омск, 2006. - 32 с.

11. Тимофеев А.А., Дакал А.В., Кишковская Е.Н. Клиническое течение одонтогенных воспалительных заболеваний челюстей и мягких тканей у больных наркоманией // Современная стоматология. - 2009. - №1. - С. 94-98.

12. Фурсова А.Д. Патогенетические особенности стоматологического статуса и лечения наркоманов в зависимости от стажа опиоидной зависимости и выраженности абстинентного синдрома: автореф. дис. док. мед. наук. - Москва, 2009. - 20 c.

13. Davis R.K., Baer P.N. Necrotizing ulcerative gingivitis in drug addict patient being withdrawn from drugs: Report of two cases // Oralsurg oral med oral pathol. - 1979. - №31. -P. 200-204.

14. Cugno F.D., Peres C.J., Tocci A.A. Salivary secretion and dental caries experience in drug addict // Arch. oral, biol, 1981. №5. - P. 363-367.

15. Du M., Bedi R., Guo L. Oral health status of heroin users in a rehabilitation centre in Hubei province, China // Community Dent. Health. 2001. - Vol. 18, №2. - P. 94-98.

16. Fazzi M., Vescovi P., Savi A. The effect of drugs on the oral cavity. [Article in Italian] // Minerva Stomatol. 2001. - Vol. 48, №10. - P. 485-489.

17. Single S. et al. Morbiditi and mortality to alcohol, tobacco and illicit drug use in Canada // Amer.J.publ.Health. - 1999. - Vol. 89, №3. - P.385-390.

18. Tilsas A. Impact of opioid use on dentistry //A HSU. Dent. J.2002. - Vol.47. - P. 94-98.

19. Yukna R.A. Cocaine Periodontitis // Mem j. periodonl. restor. dent. - 2009. Vol. 49. - P.73-79.

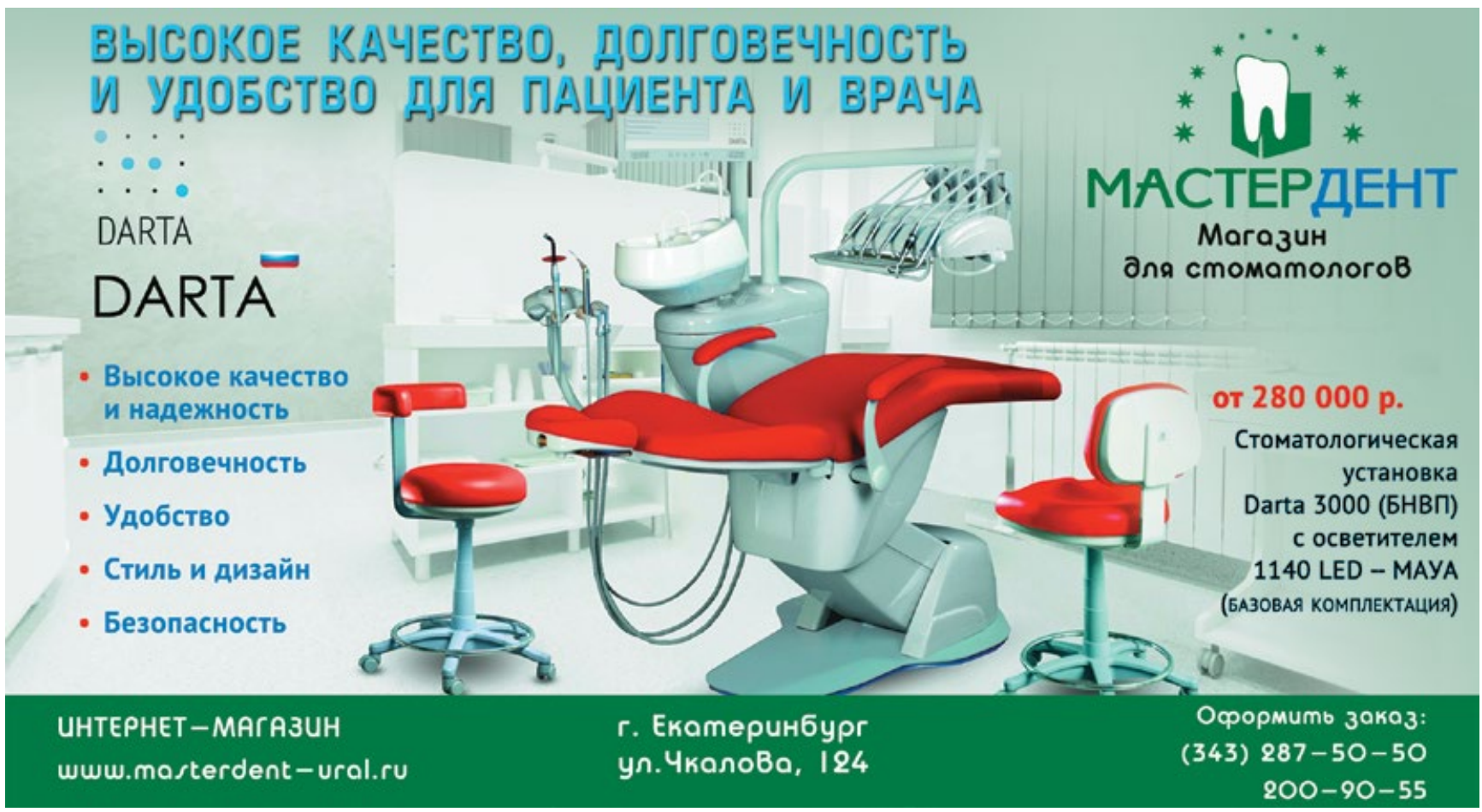

